\title{
O Sphan e a cultura museológica no Brasil
}

\section{The Historical and Artistic National Patrimony Agency and museum culture in Brazil}

Letícia Julião

O extenso legado deixado pelo Estado Novo nas relações entre a cultura e a política é fato amplamente reconhecido pelos meios intelectuais e políticos, em particular, no tocante à tradição preservacionista fundada pelo antigo Serviço do Patrimônio Histórico e Artístico Nacional - Sphan. Embora nas últimas décadas a política patrimonial tenha alcançado horizontes mais democráticos, a concepção herdada dos anos 1930 e 40 de um patrimônio circunscrito aos referentes de uma cultura ilustrada, concebida no singular, deixou vestígios que sobrevivem ainda nos meandros do aparelho burocrático, disputando a hegemonia na agenda das políticas de memória no país.

Os estudos sobre o processo de institucionalização dessa política no Brasil, muitos dos quais ensejados pelo desafio de ultrapassar os limites de sua tradição estadonovista, focalizam, em geral, a formulação do discurso patrimonial e

Letícia Julião é superintendente de museus do estado de Minas Gerais (leticiajuliao@uol.com.br). Artigo recebido em 29 de dezembro de 2008 e aprovado para publicação em 4 de março de 2009.

Estudos Históricos, Rio de Janeiro, vol. 22, n 43, janeiro-junho de 2009, p. 141-161. 
as medidas de proteção do acervo arquitetônico, cerne da ação governamental. Poucos mencionam as iniciativas no campo dos museus, e quando o fazem dedicam-lhes exames pontuais, como apên dices da obra maior daquela instituição. ${ }^{1}$

É notório que as realizações museológicas do Sphan foram de modo geral tímidas se comparadas à proteção que dispensou ao patrimônio edificado; a criação de novos museus não era a tônica de sua política, assim como não foram os tombamentos de acervos ou instituições museais. ${ }^{2}$ Mas a despeito de figurar em um plano secundário na agenda preservacionista, o Sphan inaugurou experiências que podem ser consideradas um divisor de águas no campo museológico. E não poderia ser diferente, considerando não apenas o caráter inovador da política patrimonial que então se implantava e à qual as ações museais se filiavam, como também o fato de que eram formulações que se teciam sob a égide do Estado Novo. E os estados novos, europeus ou periféricos, foram regimes profícuos na condução e no enquadramento político da cultura (Pandolfi, 1999: 17-20), processo do qual os museus não escaparam.

$\mathrm{O}$ arsenal de conhecimentos e de recursos mobilizados e construídos para alicerçar a preservação de monumentos históricos e artísticos se fará presente também no conjunto de ações museais do Sphan que, pela primeira vez no país, eram orquestradas em âmbito nacional. Assim como ocorreu com o ideário e as experiências de preservação do patrimônio, também o modelo de museu, concebido e materializado na conjuntura autoritária da Era Vargas, sobreviveu a regimes políticos que lhe sucederam nas décadas seguintes, conformando uma herança ideológica e institucional que ainda resiste em muitos museus do país.

As principais iniciativas museológicas do Sphan, entre as décadas de 1930 e 50, se localizaram, em geral, fora do eixo Rio-São Paulo, em estados como Rio Grande do Sul, Santa Catarina, Goiás, Pernambuco e, sobretudo, Minas Gerais. Menos ambiciosos que os grandes museus nacionais das duas maiores metrópoles do país, Rio de Janeiro e São Paulo, os chamados museus regionais não apenas conformaram a tradução museológica do pensamento patrimonial forjado pelo Sphan, como operaram, pode-se dizer, uma virada silenciosa na cultura museológica do país que, no entanto, é pouco reconhecida pela literatura especializada.

A museologia desenvolvida pelo Sphan - critérios e pressupostos que orientaram a formação das coleções, linguagem expositiva, atividades de pesquisa, conhecimentos e profissionais mobilizados - trazia a marca da ruptura com experiências congêneres que lhe antecederam. Segundo Lygia Martins Costa (2002: 82-83), estavam presentes nos museus das Missões, da Inconfidência e do Ouro, demarcando um diferencial com a tradição museológica do país, "a intenção científica latente e o bom gosto na apresentação, que correspondiam ao espírito de uma geração cultivada". 
Na raiz dessas inovações estavam mudanças de alcance muito mais extenso que meras questões de gosto ou de procedimentos museológicos. As iniciativas do Sphan davam curso a um processo análogo àquele verificado, a partir do século XVII, na Europa, quando, segundo Pomian (1987: 61-80), a prática colecionista amadora cedeu lugar a uma alicerçada no conhecimento sistematizado e objetivo, envolvendo homens de ciência e especialistas. A exemplo das mudanças de conteúdos das coleções ocorrida no velho continente, o bom gosto e a intenção científica identificados pela autora nos museus do Sphan eram, de fato, sinais de um novo ordenamento das relações entre os saberes e as formas de representação do mundo. Ascendia ao espaço museológico uma nova maneira de a sociedade conceber o seu passado e de gerir sua herança, balizada na percepção aguda de que o país vivia transformações substanciais. Concretamente, novas conexões entre as dimensões temporal e espacial entram em cena, destronando conteúdos históricos e de coleções, até então valorizados, e induzindo a padrões inovadores de exibir e de ver os objetos.

\section{Passado reinterpretado e colecionado}

Em 1937, quando o Sphan foi criado, o país já havia acumulado uma longa trajetória no campo museológico, especialmente no campo das ciências naturais, iniciada com a criação, em 1818, por Dom João IV, do Museu Real, mais tarde chamado Nacional. Antes disso, no final do século XVIII, poucas experiências colecionistas tiveram lugar no Brasil. Todas resultavam de investidas científicas da Metrópole no território colonizado, geralmente restritas à coleta, à preparação e ao envio de espécies para Portugal. São exemplos dessas experiências a Casa dos Pássaros, laboratório de história natural criado em 1784, no Rio de Janeiro, e as atividades do naturalista Frei Mariano da Conceição Veloso, cujas expedições de coleta também se iniciaram na década de 1780 (Heynemann, 1999).

Quando, portanto, o Sphan entra na cena museológica brasileira, o país já havia, de certa forma, cumprido o movimento traçado historicamente pelos museus no mundo ocidental de institucionalização das ciências naturais. Percorrera, entre fins do século XVIII e início do XX, um arco de diferentes arranjos entre coleções e saberes, compreendendo formatos institucionais distintos que iam do entreposto de coleta metropolitana ao museu especializado, trajeto que consolidou institutos de relevo científico, responsáveis pelo estabelecimento de normas metodológicas, pela formação profissional e pela inserção do Brasil na comunidade científica e museológica internacional (Schwarcz, 1993: 67-98).

Dessa tradição da museologia nas ciências naturais, que apresentava sinais inegáveis de decadência nos anos 1930, pouco ou quase nada o Sphan herda- 
ria, a não ser o fato de o Museu Nacional ter sido incorporado aos quadros institucionais do Ministério da Educação e Saúde (MES), por um curto período de tempo, entre 1941 e 1945. No entanto, nem a concepção nem as atividades do mais antigo museu brasileiro sofreriam alterações em seu curso sob a gestão do novo órgão, como também pouca influência a instituição secular exerceria nas formulações museais do grupo responsável pela política patrimonial. De fato, a área de atuação por excelência do Museu Nacional, as ciências naturais e as disciplinas correlatas, a exemplo da antropologia, arqueologia, paleontologia e etnografia, estava fora do horizonte visado pela política patrimonial desenhada para o país. O diretor do Sphan, Rodrigo M. F. de Andrade, em balanço que faz da instituição na década de 1950, admitia que o órgão pouco fizera em relação ao patrimônio arqueológico, cuja proteção "permaneceu a cargo do Museu Nacional, não tendo podido, por enquanto, a Diretoria do Patrimônio Histórico e Artístico assumir a responsabilidade de sucedê-lo nessa tarefa" (Andrade, 1952: 108).

Não se pode dizer o mesmo, no entanto, em relação ao Museu Histórico Nacional (MHN). Não que o Sphan tenha feito incursões para promover mudanças no museu concebido e implantado em 1922 por Gustavo Barroso, oponente histórico do grupo de intelectuais responsáveis pela política patrimonial do Estado Novo. Apesar de incorporado também aos quadros do MES, o MHN manteve-se relativamente fiel à sua plataforma fundadora, ainda que em dissonância com conceitos cultivados pelo Sphan (Williams, 2001: 149-150 e 177-179). O interesse em relação ao MHN era de outra ordem: concentrava-se na esfera das ideias, na importância de interpor e firmar conceitos que contrariavam a imaginação histórica e museológica de Gustavo Barroso. Afinal, o Museu partilhava o mesmo campo disciplinar visado pelo grupo do Patrimônio, ou seja, a história e o acervo legado pelo passado ao presente.

Enraizado na tradição antiquária e na perspectiva pedagógica da história magistra vitae (Magalhães, 2003: 106), o colecionamento do Museu Histórico Nacional sustentava-se nas chamadas ciências auxiliares da história - a heráldica, a numismática, a arqueologia ou a genealogia - privilegiando objetos-relíquias associados a fatos e a personagens notáveis do passado, considerados exemplares para o presente. Filiado à concepção historiográfica do IHGB, o Museu celebrava a nação brasileira como uma continuidade do Estado português, espécie de "desdobramento, nos trópicos, de uma civilização branca e europeia" (Guimarães, 1988: 8). Numa visão passadista e nostálgica do passado, identificava a nação como obra exclusiva do Império, sustentada em dois pilares - a nobreza e o exército (Abreu, 1996: 193)-, espécies de fios condutores que ensejavam a prática colecionista de moedas, espadas, louças, joias, brasões, bandeiras e canhões.

Com o Sphan, uma nova matriz histórica ganha os espaços dos museus. Em lugar do Império, tornam-se protagonistas do passado a sociedade setecen- 
tista, a arte colonial, a estética barroca e o movimento da Inconfidência. ${ }^{3}$ Categorias de objetos antes valorizadas caem no ostracismo e novas tipologias de acervos, assim como formas inéditas de exibi-los, comandam as experiências museais do Sphan. O privilégio dos saberes eruditos e antiquários, assim como o foco exclusivo no passado, cedem lugar ao interesse cognitivo e colecionista mais abrangente, que se estende ao campo da arte e da estética. À paixão colecionadora pelas coisas antigas, típica de antiquários e amadores, o Sphan, sob a direção de Rodrigo M. F. de Andrade, buscou imprimir um caráter científico às coleções dos museus, assim como o fez no trato de todo o patrimônio.

Segundo Francisco Iglésias (1968: 12), uma das maiores contribuições de Rodrigo M. F. de Andrade teria sido o fato de se opor ao "impressionismo crítico ou voos de imaginação, com o romanceamento ou o lirismo fácil", em nome da investigação objetiva da história da arte, fundada no rigor metodológico e no uso de fontes primárias. Exigia de toda repartição, destaca Mário Barata (1968: 4), "a conexão dos objetos com os documentos e essa coerência veio a estabelecer-se num eixo primoroso em vários pontos do país". Em carta ao Cônego Raimundo Trindade, então diretor do Museu da Inconfidência, Rodrigo M. F. de Andrade, numa crítica à falta de rigor metodológico da história da arte no país, assinala a linha divisória pretendida para o trabalho do Sphan:

(...) nos estudos relacionados com a história da arte no Brasil, há necessidade imperiosa de utilização maior possível de semelhante documentação [de ordens religiosas], uma vez que até agora a matéria esteve entregue quase exclusivamente ao trato de amadores e às suas conjeturas (Correspondência, 22/5/1951).

Entre as ações que antecediam a implantação dos museus, a formação dos acervos era tarefa da qual Rodrigo M. F. de Andrade se ocupava diretamente. Para assegurar critérios rigorosos na aquisição de objetos, demandava a peritos e artistas pareceres que consubstanciavam suas decisões. Francisco Marques dos Santos, J. Wasth Rodrigues, Gustavo Barroso, Alberto da Veiga Guignard, Djalma Guimarães, Sylvio de Vasconcellos e Antonio Joaquim de Almeida eram alguns nomes a quem Rodrigo M. F. de Andrade recorria para balizar as avaliações de acervo. ${ }^{4}$ Como museológa, especialista em história da arte e funcionária do Sphan, Lygia Martins Costa exerceu papel importante na sistematização e aplicação de conhecimentos que subsidiaram a constituição e a gestão das coleções. É o que se pode verificar em um de seus pareceres, exemplo da autoridade conquistada pelo discurso da história da arte, em que os critérios de autenticidade assinatura, datação, localização - e de envergadura artística se tornam decisivos: 
Trata-se de peça de caráter monumental, de belas proporções e de fino acabamento, com acentuado gosto clássico romano. Internamente, a julgar pelo detalhe centro-superior que temos em mão, mantém-se um tanto preso aos moldes de nossos oratórios tradicionais, com crucifixo central e os santos abarrocados dispostos lateralmente em peanhas, sobre fundo pintado de querubins. Todavia a fotografia de seu aspecto exterior deixa ver certa inovação, tanto na colocação de santos sobre a mesa do altar, como na disposição de dois vasos entalhados com flores no supedâneo (Informação n. 228, 26/09/1961).

Outros documentos relativos aos acervos museológicos se somam aos pareceres como provas dos novos pressupostos que passavam a orientar a constituição de coleções. Antônio Joaquim de Almeida, responsável pela organização do Museu do Ouro e seu primeiro diretor, justificava, por exemplo, a incorporação de arte popular àquela instituição, argumentando sobre a importância para os estudos históricos e sociais de objetos como esculturas de madeira e barro cozido, "ex-votos" ou instrumentos musicais de festas de reisado (Correspondência, 31/12/1945).

Ainda que tenham surgido como um programa marginal em relação ao principal foco da política preservacionista, as iniciativas museológicas do Sphan não apenas se beneficiaram da produção de conhecimento ensejada pela gestão do patrimônio, como também concorreram decisivamente para a geração desse corpus científico. Como se pode observar, não se tratava de reunir objetos sob a ótica exclusiva da relíquia, ou seja, objetos cuja virtude residia no fato de terem tido contato com personagens e acontecimentos do passado. Os novos critérios repousavam, sobretudo, na ideia de objetos exemplares da cultura e do gênio artístico do passado, o que exigia um investimento de conhecimento muito mais extenso para sua identificação do aquele comumente mobilizado para a comprovação das relíquias. Se a investigação de procedência bastava para a comprovação da relíquia, a exemplaridade do objeto requeria, além da origem, o reconhecimento de traços característicos do estilo, envolvendo análises nos planos material e simbólico, técnico e estético.

Eis aí o que demarcava a distinção do modelo museológico do Sphan: ele se constituíra e se consolidara alicerçado em um corpus científico gerado e desenvolvido no interior da instituição. Porque uma rede de pesquisa sustentada pela estrutura descentralizada do serviço de patrimônio pouco a pouco se articulou em todo o país, em uma dinâmica que pode ser acompanhada pela correspondência assídua de Rodrigo M. F. de Andrade com seus funcionários e colaboradores (Sub-Série Representantes. Rodrigo M. F. De Andrade. Correspondência [1928-69]). 
Em linhas gerais, secundavam a produção de conhecimento sobre o patrimônio as investigações bibliográficas e documentais, pesquisas de campo e registros fotográficos, procedimentos que lograram fixar uma metodologia de pesquisa no terreno do patrimônio, explorar massas documentais inéditas, acumular um volume considerável de informações e documentos históricos, e ensejar a publicação de vários estudos, muitos dos quais veiculados na própria revista do Iphan (Santos, 1996).

Em particular, na formação dos acervos dos museus articulavam-se pesquisadores, peritos de arte, funcionários e diretores de museus, representantes da Igreja e antiquários que começavam a movimentar um mercado nascente de "coisas antigas", enredados todos em uma teia de relações sociais, que iam de laços pessoais e familiares até contatos com moradores de pequenos núcleos urbanos e áreas rurais. Trocas de informação, buscas e descobertas de preciosidades insuspeitadas, exames cautelosos seguidos de formação de juízos sobre as peças construíam pouco a pouco os cânones do conhecimento sobre as "antiguidades nacionais". Pela primeira vez no país se fazia uma investida desse porte; representantes do poder público efetivam práticas colecionistas e coleções, balizados por critérios e conhecimentos que se pretendiam científicos e específicos, produzidos no interior do Sphan (Julião, 2008: 190-200).

Alguns exemplos de avaliações de especialistas de peças para aquisição são elucidativos desses novos parâmetros que passam a orientar o colecionamento público. Em 1951, Rodrigo M. F. Andrade escreve a Sylvio de Vasconcellos recomendando a aquisição de uma mesa, que José Wasth Rodrigues destacava tratar-se "de obra de mobiliário regional de marcada originalidade e cuja incorporação ao patrimônio dos museus subordinados a esta repartição é indispensável" (Correspondência, 18/10/1951). Em parecer de 1946, opinando sobre um conjunto de móveis da região de Diamantina, Francisco Marques dos Santos assinalava algumas peças de interesse para aquisição, a exemplo de um canapé e uma cadeira, "modelos interessantes e já escassos em Minas", exemplares do tipo Sheraton: "inicialmente importado da Inglaterra para Minas, aí tomou interessantes características locais" (Correspondência, 18/01/1946). Em 1961, Lygia Martins Costa se pronuncia favorável à aquisição de um instrumento de suplício em razão de sua procedência: "Parece-me conveniente a sua aquisição, não só por se tratar de elemento da própria cidade de S. João Del Rei, como também por caber na seção que estamos organizando no $3^{\circ}$ andar do prédio de arte e artesanatos populares do séc. XIX” (Manuscrito, 15/05/1961).

Por vezes, era o próprio Rodrigo quem se pronunciava a respeito das peças, como na carta expedida ao Cônego Trindade: "Fiquei extremamente interessado pela aquisição tanto do oratório como das 2 imagens de Santana, mas sobretudo pela do oratório, peça em verdade excepcional" (Correspondência, 
29/09/1952). O mesmo ocorre em relação a um armário almofadado procedente de Mariana: "Achei o armário uma peça notável e ainda estou dando tratos à bola para ver de que maneira conseguiremos adquiri-lo, assim como aqueles móveis embutidos dos Hélio Hermeto e antes a joia de ouro" (Correspondência, 14/09/ 1946). Porém, a prática usual era o diretor do Sphan enviar recomendações de aquisições aos diretores de museus ou a Sylvio de Vasconcellos, chefe do escritório em Belo Horizonte, acompanhadas de parecer de perito (Correspondência, 04/12/1945).

Como se pode notar, os termos excepcional, notável, de marcada originalidade, de características locais e raridade eram qualificativos que franqueavam a aquisição dos objetos. Denotavam muito mais uma preocupação com a qualidade de fatura dos objetos, com as características da técnica regional, com o seu valor de ruína - tanto como testemunha que o tempo destrói, como metáfora de caducidade - que com algum aspecto associado a experiências particulares da história local ou os seus nexos com a história nacional.

\section{Civilização mineira nos museus}

Não obstante as várias iniciativas museológicas na capital federal, foi nas experiências levadas a efeito em outros estados que o Sphan pôde projetar, de fato, uma plataforma museal correlata à concepção de patrimônio formulada e disseminada pela política preservacionista dos anos 1930 e 40 . Nos museus em que se encarregou de todas as etapas para sua constituição, aí compreendida a formação dos acervos, o Sphan pôde ensaiar novas vertentes colecionistas, formas alternativas de exibição de objetos e novos discursos museográficos. No Distrito Federal, além de ter herdado museus já constituídos - Nacional e Histórico Nacional -, aqueles que criou, a exemplo do Nacional de Belas Artes e o Imperial, já dispunham de núcleos de acervos preliminares. O Museu Nacional de Belas Artes formou-se a partir do acervo da antiga Academia Imperial de Belas-Artes, e o Museu Imperial teve sua origem associada ao antigo Museu Histórico de Petrópolis, herdando inclusive seu patrimônio. ${ }^{5}$

O primeiro empreendimento museológico do Sphan ocorreu no Rio Grande do Sul, com o projeto do Museu das Missões, iniciado em 1938, ao qual se seguiram outros, sendo o estado de Minas Gerais o mais beneficiado. ${ }^{6} \mathrm{~A}$ justificativa de Rodrigo M. F. de Andrade para uma política francamente favorável ao seu estado de origem era assinalar, assim como o fizera com os bens arquitetônicos, o caráter singular do patrimônio móvel mineiro, cujo valor superava os interesses regionais, merecendo, portanto, a proteção nacional. Além de possuir “o núcleo mais denso do acervo nacional" (Andrade, 1987: 60), a constituição de 
uma verdadeira rede de museus em Minas era defendida como medida indispensável para fazer frente às perdas crescentes do acervo do estado. Considerando a grandeza de sua herança patrimonial, dizia Rodrigo M. F. de Andrade, em 1956: "O número de museus organizados em seu território é ainda bastante reduzido e o respectivo acervo não impressiona pela riqueza antes pela modéstia”. Isso porque, implantados tardiamente, lamentava, os museus não puderam impedir a evasão de importantes obras do patrimônio mineiro, subtraídas por comerciantes de antiguidade (Andrade, 1987: 154-156).

Criados entre os anos 1930 e $1950,{ }^{7}$ os museus da Inconfidência, do Ouro, do Diamante e Regional de São João Del Rei significativamente distribuíam-se pelas quatro antigas comarcas da Capitania das Minas - Vila Rica, Sabará, Serro do Frio e Rio das Mortes - o que permitia assegurar uma atuação museal a toda extensão geográfico-administrativa da empresa colonial na sociedade mineradora. Organizados nos principais núcleos urbanos coloniais de Minas, antigas cabeças de comarcas, à exceção de Diamantina, os museus lograram musealizar vestígios de uma cultura concebida como civilização. Eram instituições que resultavam e, ao mesmo tempo, concorriam para a produção de um discurso baseado na premissa de que, na conformação do fenômeno urbano e nos seus desdobramentos culturais, encerrava-se o grande legado das Minas para o país. Celebravam, portanto, uma civilização vista como germinal da brasilidade, e cujo documento mais visível de sua existência eram exatamente as estruturas urbanas sobreviventes dos séculos XVIII e XIX.

O discurso consagrado pelo Sphan de identificação da sociedade mineradora com a origem da própria nacionalidade deve muito ao pensamento de Afonso Arinos de Melo Franco. Em particular ao seu conceito de civilização brasileira que, pode-se dizer, constituiu-se em uma chave interpretativa do discurso patrimonial legitimado nos anos 1930 e 1940 . Além da interlocução permanente que mantinha com Rodrigo M. F. de Andrade, Arinos ministrou um curso para o grupo de funcionários do Sphan em 1941, cujas palestras foram publicadas em 1944 com o título Desenvolvimento da civilização material no Brasil. Nessa e em outras obras, o autor faz coincidir a ideia de "civilizações" com aquela de ciclos econômicos, inscrevendo, assim, a marcha civilizacional em trajeto marcado pelos ápices de riquezas geradas no país e seus consequentes rastros materiais. Considerada a cultura realizada, a civilização é definida, pelo autor, como o aproveitamento que o homem faz do mundo para satisfazer suas necessidades, o que implicaria técnica e distintos graus de qualidade de vida. Nessa escala evolutiva, defendia, as culturas que interessam, de fato, são aquelas que transmitem à posteridade sua concepção e interpretação do mundo (Franco, 1936).

A partir dessas premissas, as Minas do século XVIII eram apontadas como a civilização de fato notável do passado brasileiro; em seu território a fixa- 
ção do homem havia se materializado em uma rede de cidades, a economia do ouro alcançara importância internacional e a vida urbana se traduzira em civilidade e ambiente propício ao cultivo das artes e da cultura. Todos esses fatores sustentavam a convicção de Arinos, compartilhada pelo Sphan, de que "sob o ponto de vista de civilização brasileira, a contribuição das Minas é insuperável e inesquecível"; uma civilização que figurava como "talvez a mais alta do continente americano naquele século, tão alta como o próprio Reino não conheceu na mesma época" (Franco, 2007: 118 e 107).

Na visão de Rodrigo M. F. de Andrade, no intervalo de um século Minas Gerais havia produzido um acervo que, se não poderia ser identificado como legado de uma civilização autêntica, testemunhava a ocorrência, no domínio das artes, de uma escola mineira:

Foi necessário o transcurso de longo tempo para reconhecer-se que as condições particulares de Minas Gerais tinham produzido de fato, no lapso breve de pouco mais de um século, obras de literatura, ciência, música, arquitetura, pintura, escultura, e de artes menores, cujo acervo, se não justifica, é claro, a conclusão por demais ambiciosa de considerá-lo espólio de uma autêntica civilização, constitui, todavia, fenômeno que, pelo menos no domínio das artes, testemunha a ocorrência irrecusável de uma escola mineira, com traços próprios e bem vinculados, permitindo identificá-la nas obras de feição erudita ou popular aqui realizadas. (Andrade, 1987: 170)

Um conjunto de extensos vestígios da sociedade deveria ser preservado não apenas em nome do apuro estético, mas também e, sobretudo, como documento de um "espírito" comum que se disseminara, de maneira rara na história do Brasil, a todos os aspectos da vida nas Minas. Concretamente isso significou vislumbrar como alvo da ação preservacionista outros aspectos da vida intelectual, artística, moral e material que iam muito além do acervo monumental arquitetônico. Vestígios do ambiente urbano, da atividade mineradora, das formas de trabalho, dos rituais religiosos, dos modos de viver, comer, vestir e conviver, da vida pública e da incipiente vida privada; todos esses elementos dão entrada em museus criados para preservar e consagrar a civilização do ouro.

Que outro meio senão os museus para melhor mostrar uma cultura realizada pelo engenho, técnica e gênio de uma sociedade? Da louça à imaginária sacra; de pequenos objetos utilitários, tais como candeias, caldeirões, mata-borrões ao mobiliário de residências; de peças do vestuário, joias e instrumentos de música ao produto das lavras das minas; dos instrumentos de trabalho às estru- 
turas urbanas; tudo concorria como índice da vida intelectual, artística, cotidiana e material da sociedade mineira dos séculos XVIII e XIX.

Comungando o mesmo propósito de reverenciar a suposta civilização mineira, os museus da Inconfidência, do Ouro, do Diamante e Regional de São João Del Rei circunscrevem uma zona de cruzamento museal, fixada pela semelhança de suas práticas de colecionamento e de suas interpretações do passado mineiro e brasileiro. A despeito das diferenças de porte, da abrangência e do volume específicos de seus acervos ou de terem sido criados em contextos políticos distintos, esses museus não apenas são de natureza semelhante como também conservam fortes ligações de reciprocidade.

Ao se encarregarem da preservação da herança cultural de partes da história das Minas - a extração do ouro, do diamante, o movimento da Inconfidência, a sociedade nos séculos XVIII e XIX - eles funcionam como elementos que se complementam e que concorrem simultaneamente para fixar e potencializar uma mesma imagem do passado. Referenciam todos a mesma matriz histórica, cujo enredo, evocado por meio do repertório fixo de objetos, traduz uma imagem idealizada da sociedade mineradora, na qual predominam a herança da cultura barroca e católica e de um universo estético erudito e materialmente requintado.

Uma análise de inventários e listas ${ }^{8}$ de acervos desses museus corrobora a ideia de que eles de fato formavam uma espécie de rede museal, a despeito de pequenas variações na predominância de determinadas categorias de acervo. A convergência de tipologias dos objetos não é senão a tradução de pressupostos e de critérios partilhados pelos museus. Não apenas os mesmos conceitos perpassam os quatro museus, como conduzem à formação de suas respectivas coleções, estabelecendo relações estreitas entre as peças escolhidas para integrar a coleção e a ideia de sua musealização.

Três classes de objetos se sobressaem nos três museus. É notável o predomínio de objetos de arte sacra e de mobiliário, categorias que disputam a primazia sobre as demais. Destacam-se também os utensílios e objetos domésticos aqui compreendidos os serviços de cozinha e de mesa e equipamentos de trabalho, que avultam, particularmente, no Museu do Diamante. Algumas categorias se distinguem por museu: objetos de iluminação, livros e textos impressos, acessórios de decoração, insígnias, transporte e seus apetrechos e fragmentos construtivos sobressaem no Museu da Inconfidência; objetos pecuniários e armas no Museu do Diamante; objetos de culto e de cerimoniais e fragmentos construtivos no Museu Regional de São João Del Rei.

É possível afirmar que os acervos dos quatro museus formam um conjunto que estampa vestígios da civilização mineira, tal como postulava o ideário do Sphan. Tachos, louças, talheres, mobiliário, arcas, objetos de higiene pessoal, 
oratórios, candeias, desenham um universo doméstico composto de ambientes nobres, com interiores guarnecidos por utensílios e objetos de conforto, sinalizando a existência, no mundo privado, de hábitos requintados, dignos de uma civilização. Uma imagem do fausto, sugerido pelo acervo exposto nos museus, e que a pesquisa histórica irá contestar, ao evidenciar um cotidiano próximo da precariedade, desprovido de comodidades, comum à maioria absoluta da população (Souza, 1982). Grande parte das peças em exposição, pela singularidade, raridade ou excelência da fatura eram, sobretudo, exceções, e não o padrão encontrado na sociedade mineradora.

Do espaço público, havia um repertório menos variado, mas ainda assim significativo do emblema maior postulado pela ideia de "civilização do ouro", qual seja, a vida urbana: cadeirinhas de arruar, luminárias, fragmentos construtivos, instrumentos de trabalho como os de mineração, armas, acessórios de montaria, instrumentos musicais, tinteiros e penas de escrever, marcos de sesmarias de vilas.

Entre as categorias de objetos, aquelas ligadas à vida religiosa e à Igreja predominavam nas coleções, as quais abarcavam desde a imaginária, objetos processionais e litúrgicos, incluindo prataria, paramentos e alfaias, até o mobiliário integrado à arquitetura religiosa, a exemplo de retábulos e das pias batismais. $\mathrm{O}$ destaque conferido a esse tipo de acervo deve ser compreendido, em parte, como retrato da própria história colonial, quando a supremacia da Igreja conferia-lhe o papel de principal promotora de festas, cerimônias e rituais públicos, patrocinadora das artes e do saber. Como centro de poder e sociabilidade, figurava como importante núcleo gerador da cultura material da Colônia, sendo, portanto, como assinala Rodrigo M. F. Andrade "de propriedade das Dioceses, das corporações religiosas e das ordens terceiras ou irmandades o acervo mais numeroso e mais rico de bens móveis e imóveis de valor artístico e histórico existentes no país" (Andrade, 1952: 76).

Se os museus tiveram na Igreja a principal fonte de aquisição de seus acervos (Trindade, 1958: 65; Andrade, 1952: 76), contaram também com outras instituições ou mesmo com particulares como doadores ou parceiros em transações para aquisição de peças. Convém lembrar, a título de exemplo, o acervo integrado por intermédio de Vicente Racioppi ao Museu da Inconfidência, proveniente do Instituto Histórico e Geográfico de Ouro Preto; e a compra da coleção de Antônio Coimbra, efetuada em 1947, para o Museu do Diamante (Correspondência, 07/05/53; Correspondência, 31/07/1957).

Ainda que recorresse a estratégias diversificadas na constituição dos acervos museológicos, é notório o rigor com que o Sphan selecionava e restringia a incorporação ou exibição de peças, de modo a assegurar a prevalência conceitual dos museus. Veja-se o caso da coleção de Vicente Torres, cuja família manifes- 
tara interesse em que fosse dado o nome deste à sala onde os objetos estivessem expostos. Apreciando a solicitação, Rodrigo M. F. Andrade é categórico:

Não vejo inconveniente algum, antes pelo contrário, em denominar determinado recinto do museu. O que não é desejável e talvez não se possa aceitar é o compromisso de expor todas (grifo de Rodrigo M. F. Andrade) as peças porventura doadas ou mesmo o de expô-las reunidas em certa sala. De fato há probabilidade de alguns objetos da coleção não possuírem os requisitos necessários para serem exibidos permanentemente no museu, além disso, será do maior inconveniente nos obrigarmos a colocar as peças da coleção Torres não de conformidade com o critério que se nos recomendar e sim apenas com o propósito de mostrá-las em conjunto (Correspondência, 15/09/1955).

Mesmo que a proposta de Rodrigo M. F. Andrade corroborasse a prática corrente de perpetuar o nome de doadores de acervos ou benfeitores em salas dos museus, é indiscutível que rompia com uma convenção usual de reservar espaços exclusivos para a exibição de conjuntos de coleções recebidas em doação. Desfazia-se assim a ideia do museu-memorial, lugar de consagração de representantes das elites consubstanciada em coleções, objetos ou benefícios que eram legados aos museus de modo a perpetuar a memória de seus doadores. Tratava-se de assegurar uma narrativa cuja lógica era definida a partir de parâmetros civilizacionais ou estéticos previamente definidos pelo corpo técnico do Sphan, e para os quais pouco importava a procedência familiar ou social dos acervos. Ainda que os critérios colecionistas recaíssem sobre objetos oriundos do universo material das elites, não se tratava mais de consagrar pessoas ou fatos isolados, orientação diametralmente oposta àquela que irá marcar grande parte dos museus históricos, com destaque para o Museu Histórico Nacional (Abreu, 1996).

\section{Patrimônio mineiro: da nação para o mundo}

Por mais de 30 anos, a atuação do Sphan, de uma maneira ou outra, nutriu o imaginário de uma cultura e arte das Minas setecentista como expressões de um espírito autóctone, por isso mesmo germe da nacionalidade. Civilização mineradora e barroco eram matrizes histórico-culturais que convinham ao desafio de produzir um patrimônio capaz de operar uma identidade nacional unificada e, ao mesmo tempo, credenciar o país a participar do "concerto das nações" cultas. Em especial, a consagração do barroco ${ }^{9}$ permitiu esse movimento duplo e 
sinérgico entre o particular e o universal: sua preservação importava na ideia de proteger o que de melhor o "gênio humano" havia produzido no Brasil e que, sem perder sua singularidade nacional, partilhava de uma linguagem cujo repertório estava afinado aos parâmetros da arte ocidental.

Balizavam esse discurso algumas ideias sintetizadas assim por Rodrigo M. F. de Andrade: o estilo mineiro do período colonial, "sem exagero de pretensão regionalista", trazia a marca do refinamento estético, da originalidade, das feições eruditas e nobres. Além da importância incomparável no campo da pintura e escultura, oferecia também "a melhor contribuição da arquitetura brasileira para o patrimônio artístico universal" (Andrade, 1987: 74- 75 e passim).

A partir dessa matriz interpretativa, consolida-se, na esfera do Sphan, o processo de validação do barroco como estilo nacional. Uma tese que se tornou cara a muitos estudiosos, entre os quais Sylvio de Vasconcellos, professor da Escola de Arquitetura da UFMG e chefe do serviço do Patrimônio em Minas entre 1939 e 1969. Em vários de seus escritos, irá defender a ideia de que os artistas mineiros souberam interpretar as ideias europeias que recebiam, encontrando soluções autóctones que conferiram um sabor local ao barroco na sua universalidade: "Não sabor que aparece em todo o continente, através de elementos decorativos de origem nativa, mas um sabor erudito que interfere com o próprio partido das composições" (Vasconcellos, 2004: 103).

Dando curso nos anos 1960 às formulações gestadas nos anos 40 e 50 pelos ideólogos do patrimônio, Vasconcellos explicita, em sua obra intitulada $M i$ neiridade, a dimensão do nacional nas fronteiras da cultura mineira:

Não se dão nas Minas meras transposições culturais, enxertias de galhos já em frutos, transplantadas. Nelas todas as influências se casam em semente, flores cujos polens se misturam, províncias da metrópole, da África, da Ásia longínqua, sujeitas à fermentação local, à germinação condicionada pelo solo duro, de onde brota, afinal, uma nova espécie, uma nova gente, uma nova cultura. (...) Nas Minas se condensa a tipologia nacional de todos os quadrantes, sem prevalências ou hipertrofias. (Vasconcellos, 1968: 49)

Em síntese, o barroco mineiro era identificado como manifestação de admirável originalidade, cujas soluções, prescindindo das contribuições do gosto popular ou primitivo, conservavam a nobreza erudita da arte dos povos cultos. Ali estava a melhor contribuição da cultura brasileira à galeria do patrimônio representativo da humanidade, qual seja, a herança do domínio luso, que fora inovada em terras brasileiras, conciliando e condensando influências diversas, em formas crivadas pelo gosto e refinamento. 
Concomitante à produção desse discurso e às ações concretas de preservação levadas a efeito no plano interno, o Sphan cuidou de projetar o patrimônio cultural brasileiro no cenário internacional, por meio de uma articulação criteriosa de iniciativas que compreendiam desde exposições, publicações, até divulgação em reuniões e conferências de organismos internacionais. O contato permanente de Rodrigo M. F. de Andrade e seu grupo com especialistas estrangeiros, a exemplo de Mário Chicó, (Portugal), Robert Schmitd (EUA) e, sobretudo, Germain Bazin (França), assegurou ao patrimônio e, em especial, ao barroco, o aval da crítica internacional, selando o seu destino como estilo nacional com projeção no plano global.

Se os museus do Sphan em Minas não se afiguravam instituições de porte e de envergadura necessários à projeção do país no cenário internacional, foram, todavia, cruciais para conferir coerência e legitimidade à reescrita do passado nacional levada a cabo pelo Sphan. Funcionaram, na dinâmica do jogo inevitável entre o discurso do saber e o uso político desse discurso, como documentos complementares ao conjunto dos monumentos de pedra e cal da arquitetura colonial, prestando-se a atestar a existência de uma civilização identificada como geradora da brasilidade.

Nessa perspectiva, parece pouco apropriado classificá-los de regionais. Afinal, para os "inventores do patrimônio", os acervos desses museus, ultrapassando as esferas do local, concorriam para firmar "Minas e o conjunto de valores morais e religiosos a ela associado como metáfora central para o Brasil" (Gonçalves, 1996: 71). Os museus da Inconfidência, do Ouro, do Diamante e Regional de São João Del Rei devem, portanto, ser compreendidos como parte desse processo que logrou operar a transposição do regional em nacional, um desdobramento previsível no campo museal da concepção de patrimônio nacional desenvolvida pelo Sphan.

Para além do discurso patrimonial, os artifícios da linguagem museográfica utilizados pelo Sphan foram também decisivos para a construção da perspectiva nacional/universal dos acervos museológicos. Na busca do equilíbrio entre os elementos genuínos e os valores em consonância com as normas cultas, os museus acabaram por fixar em seus discursos expositivos relações estreitas entre a história e a arte, assegurando à herança do passado transcendência no tempo e espaço.

Se a prática de colecionamento foi o instrumento que permitiu ao Sphan extrair os objetos do circuito de uso ou comercial, submetendo-os a uma proteção especial, os museus possibilitaram não apenas franqueá-los ao público, mas inscrevê-los em um texto coerente. Extraídos de seus contextos originais e singularizados no conjunto da narrativa, os objetos artefatos adquiriram valor de visualidade, aproximando-se do estatuto de objetos de arte. 
Deslocados das igrejas, dos espaços privados das antigas residências ou do universo de trabalho, e dispostos em novos arranjos, os objetos encenavam uma escrita museal a meio caminho entre a história e a poesia. Como observa Kirshenblatt-Gimblett (1991: 387-388), tratando do artefato etnográfico, na condição de ruína o objeto está informado pela poética do destacamento, a qual não se refere somente ao ato físico da sua retirada e segmentação de contextos originais, mas à atitude que o transforma em fragmento, tornando sua apreciação possível.

A esse processo de transmutação dos objetos Svetlana Alpers chama de efeito museum, ou seja, o efeito de investir os objetos de um novo estatuto no ambiente do museu, transformando-os, independentemente de suas funções originais, em obra de arte. Nessa condição, o que importa é o interesse visual que podem despertar e não necessariamente o significado cultural que testemunham (Alpers, 1991: 25-32).

Tendo o passado colonial como matriz histórica e o interesse visual como princípio a orientar a inovação do discurso museográfico, os museus da Inconfidência, do Ouro, do Diamante e Regional de São João Del Rei inscreveram-se em um domínio híbrido, onde a história, a arte e a etnografia transitam e se cruzam, ultrapassando as clivagens entre uma ou outra disciplina. ${ }^{10}$ Assim como não há nesses museus preocupação em destacar fatos ou personagens exemplares, ${ }^{11}$ também não existe uma ordem cronológica na qual os fatos se sucedem em uma linha concatenada do tempo.

Neles, o passado apresenta-se como fragmentos de imagens, instantâneos ou frações visuais do tempo pretérito, tomados como o todo. O tempo é o mesmo, eternizado, portanto repetitivo, assim como são reiterativas as narrativas construídas pelas coleções nos quatro museus.

Entre os limites da história, circunscrita aos indícios do passado, e a liberdade de criação ou recomposição pela poética, os museus criaram narrativas que lograram, não por acaso, estetizar o passado: a história reposta pela via da arte, linguagem transcendente capaz de vencer as barreiras do tempo, assim como as fronteiras geográficas, para perpetuar exemplos de beleza e de virtude. $\mathrm{Na}$ busca da universalidade, os museus do Sphan parecem abraçar o princípio aristotélico da superioridade da poesia sobre a história:

O historiador e o poeta não se distinguem um do outro, pelo fato de o primeiro escrever em prosa e o segundo em verso (...). Diferem entre si, porque um escreveu o que aconteceu e o outro o que poderia ter acontecido. Por tal motivo a poesia permanece no universal e a história estuda apenas o particular. (Aristóteles, 2005) 
Apesar das inovações que se limitaram a museus pequenos, localizados fora dos grandes centros urbanos, é preciso reconhecer que as iniciativas do Sphan germinaram uma nova cultura museológica no país. Isso porque uma nova maneira de pensar e organizar museus se colocou em curso nesses espaços; antigas razões e paixões colecionistas foram subvertidas, em nome de novos focos de interesse. Outras escolhas se impuseram na formação das coleções, assim como novas formas de ordenar e de se apropriar do mundo. Na raiz dessas mudanças estavam anseios inéditos que se lançaram do tempo presente em direção ao passado, conduzindo as coleções e suas exposições públicas a novos desígnios.

Notas

1. No Brasil, a questão do patrimônio torna-se, particularmente, objeto de reflexão acadêmica a partir da década de 1990, resultado do processo de democratização do direito à memória iniciado na década anterior. Os estudos se voltam para a formulação de novos conceitos e novas diretrizes de políticas patrimoniais, assim como para o passado da experiência preservacionista, colocando o pensamento e as práticas do antigo Sphan no foco das atenções investigativas. Entre outros trabalhos que se dedicam ao assunto, menciona-se Santos (1992); Gonçalves (1996); Rubino (1996); Fonseca (1997); Malhanos (2002); Abreu e Chagas (2003).

2. Somando os acervos, as coleções e os bens móveis isolados, o Sphan procedeu a 31 inscrições em livros de tombos, durante a gestão de Rodrigo M. F. de Andrade, ou seja, aproximadamente 4,5\% do total de 689 inscrições efetuadas entre 1938 e 1967. Cf.

Mec-Sphan/Pró-Memória (1982).

3. Sobre aspectos, períodos e perspectivas do passado eleitas pelo Sphan, cf. Rubino (1996: 96-115).

4. Um conjunto de pareceres e documentos que tratam de aquisição de acervo pode ser consultado na Sub-série Aquisição. Peças de arte (diversas). CX03 PT10, 11, 12, 13, 14 Mod. 67. Arquivo Documental do Iphan.

5. Sobre a origem do Museu Imperial, cf. Santos (2006: 94-100).

6. A prevalência de iniciativas museológicas em Minas Gerais é notória. Fora do âmbito do Distrito Federal o Sphan se encarregou, durante a gestão de Rodrigo M. F. de Andrade, da organização das seguintes instituições: Museu das Missões (Rio Grande do Sul); Museu Victor Meirelles (Santa Catarina); Museu da Bandeira (Goiás); Museu da Abolição (Pernambuco); e Museus da Inconfidência, do Ouro, do Diamante, Regional de São João Del Rei, Regional de Caeté, além das Casa dos Inficionados e Casa dos Otoni (Minas Gerais).

7. Concebido em 1938, o Museu da Inconfidência foi inaugurado em 1944. Seguiram-se a inauguração do Museu do Ouro, em Sabará (1946); a do Museu do Diamante, em Diamantina, (1954); e a do Museu Regional de São João Del Rei (1958).

8. As afirmações baseiam-se em três documentos de natureza análoga, 
referentes aos Museus da Inconfidência, do Diamante e Regional de São João Del Rei. Ainda que não tenha sido encontrado documento similar nos arquivos do Museu do Ouro, as análises podem ser estendidas a essa instituição, considerando que listas provisórias ou incompletas de seu patrimônio dão provas das semelhanças de seu acervo com os demais. Cf. Inventário, 1946; Relação, 1952; Arrolamento, 1961.

9. Vários estudos se dedicaram a analisar o processo de consagração do barroco pelo Sphan. Ver em especial Rubino

Referências bibliográficas

\section{Fontes primárias}

BARATA, Mário. 1968. Rodrigo M. F. de Andrade e a historiografia artística brasileira. Minas Gerais, Belo Horizonte, Suplemento Literário, 26 de outubro.

CORRESPONDÊNCIA de Antônio Joaquim de Almeida a Rodrigo Mello Franco de Andrade. 31/12/1945. Relatório de 1945. Caixa 3. Administrativo. Arquivo Museu do Ouro.

CORRESPONDÊNCIA de Francisco Marques dos Santos a Rodrigo Mello Franco de Andrade. 18/01/1946. Subsérie Aquisição. Peças de arte (diversas). CX03 PT11 Mód. 67. $3^{\circ}$ envelope. Arquivo Documental do Iphan.

CORRESPONDÊNCIA de Rodrigo Mello Franco de Andrade a Antonio Joaquim de Almeida. 1946. Subsérie Representante. Antonio Joaquim de Almeida. (1945-50; 1961-70). CX321
(1996); Miceli (1987); Mota (1987); Fonseca (1997).

10. A respeito dos museus de história, mas que se situam em lacunas ou cruzamentos de disciplinas, cf. Joly e Gerverreau (1996: 14-15).

11. O Panteão dos Inconfidentes é a exceção. Concebido como parte integrante do Museu da Inconfidência, dispõe de pequeno número de objetos-relíquias associados ao movimento, apresentados em uma linguagem distinta do restante do Museu.

PT05 Mód. $73.4^{\circ}$ envelope. Arquivo Documental do Iphan. 14/09/

CORRESPONDÊNCIA de Rodrigo

Mello Franco de Andrade a Antonio Joaquim de Almeida. 04/12/1945. Subsérie Representante. Antonio Joaquim de Almeida. (1945-50; 1961-70). CX321 PT05 Mód.73. $2^{\circ}$ envelope. Arquivo Documental do Iphan.

CORRESPONDÊNCIA de Rodrigo Mello Franco de Andrade a Sylvio de Vasconcellos. 18/10/1951. Subsérie Representante. Sylvio de Vasconcellos. CX 381 PT279 Mód. 74. $3^{\circ}$ Envelope. Arquivo Documental do Iphan.

CORRESPONDÊNCIA de Rodrigo Mello Franco de Andrade ao Cônego Raimundo Trindade. 29/09/1952. Subsérie Representante. Raimundo Trindade (1950-53). CX378 PT268 Mód. $74.7^{\circ}$ Envelope. Arquivo Documental do Iphan.

CORRESPONDÊNCIA de Rodrigo Mello Franco de Andrade ao Cônego 
Raimundo Trindade. 22/5/1951. Sub-série Representante. Assunto Raimundo Trindade (1950-53). Localização CX 378 PT 268 Mód. 74. Arquivo Documental do Iphan.

IGLÉSIAS, Francisco. 1968. Rodrigo e a historiografia brasileira. Minas Gerais, Belo Horizonte, Suplemento Literário, 26 de outubro, p. 12.

INFORMAÇÃO n. 228, endereçada ao Diretor Geral, assinada por Lygia Martins Costa. 26/09/1961. Arquivo Permanente. Série 1. Cidade: Diamantina. Bens Móveis. Arquivo Documental da $13^{\mathrm{a}}$ Superintendência Regional do Iphan-MG.

MANUSCRITO de Lygia Martins Costa endereçado a Rodrigo Mello Franco de Andrade. 15/05/1961. Subsérie Personalidade. Lygia Martins Costa (1958/81). CX 27, PT 96, Mód. $341^{\circ}$ Envelope. Arquivo Documental do Iphan.

SUB-SÉRIE AQUISIÇÃO. Peças de arte (diversas). CX03 PT10, 11, 12, 13, 14 Mod. 67. Arquivo Documental do Iphan.

SUB-SÉRIE REPRESENTANTES, Rodrigo M. F. De Andrade. Correspondência [1928-69] CX07 a 09 PT01 a 06 Mód.34. Arquivo Documental do Iphan.

\section{Fontes secundárias}

ABREU, Regina. 1996. A fabricação do imortal: memória, história e estratégia de consagração no Brasil. Rio de Janeiro: Rocco.

ABREU, Regina; CHAGAS, Mário (org.). 2003. Memória e patrimônio: ensaios contemporâneos. Rio de Janeiro: DP\&A.

ALPERS, Svetlana. 1991. The Museum as a way of seeing. In: KARP, I; LAVINE, S. D. (org.). Exhibiting cultures: the poetics and politics of museum display.
Washington \& London: Smithsonian Institution Press.

ANDRADE, Rodrigo Mello Franco de. 1952. Brasil: monumentos históricos e arqueológicos. México: Instituto Panamericano de Geografia e História; Instituto Nacional de Antropologia e Historia de México. (Monumentos Históricos e Arqueológicos III). 1987. Rodrigo e o Sphan. Organização de Terezinha Marinho. Rio de Janeiro: Ministério da Cultura, Fundação Nacional Pró-Memória.

ARISTÓTELES. 2005. História e poesia. In: ARISTÓTELES. $A$ arte poética. Tradução Pietro Nassetti. São Paulo: Martins Claret.

COSTA, Lygia Martins. 2002. De museologia, arte e patrimônio. Brasília: Iphan.

FONSECA, Maria Cecília Londres. 1997. Patrimônio em processo. Rio de Janeiro: UFRJ/ Minc - Iphan.

FRANCO, Afonso Arinos de Melo. 1936. Conceito de civilização brasileira. São Paulo: Cia. Editoral Nacional. 1944. Desenvolvimento da civilização material no Brasil. Rio de Janeiro: Sphan. 2007. Rosa de Ouro. Organizado por Afonso Arinos Filho. Belo Horizonte: EdUFMG.

GONÇALVES, José Reginaldo Santos. 1996. A retórica da perda. Rio de Janeiro: UFRJ/Iphan.

GUIMARÃES, Manoel Luís Salgado. 1988. Nação e civilização nos trópicos: o Instituto Histórico e Geográfico Brasileiro e o projeto de uma história nacional. Estudos Históricos, Rio de Janeiro, n. 11, p. 5-27.

GUIMARÃES, Manoel Luiz Salgado. 2003. Memória, história e historiografia. In: BITTENCOURT, José Neves; BENCHETRIT, Sarah 
Fassa; TOSTES, Vera Lúcia Bottrel (ed.). História representada: o dilema dos museus. Rio de Janeiro: Museu Histórico Nacional.

HEYNEMANN, Claudia Beatriz. 1999. Culture scientifique et collections d'histoire naturelle dans le Brésil du XVIII ${ }^{\mathrm{e}}$ siècle. In: RIBAULT, Jean-Yves (org.). Mécènes et collectionneurs. Actes du $121^{\mathrm{e}}$ Congrès National des Sociétés Historiques et Scientifiques, Section Histoire Moderne et Contemporaine, Nice, 1996. vol. 1: Les variantes d'une passion.

JOLY, Marie-Hélène; GERVERREAU, Laurent. 1996. Musées et collections d'histoire en France. Guide. Association International des Musées d'Histoire.

JULIÃO, Letícia. 2008. Enredos museais e intrigas da nacionalidade: museus e identidade nacional no Brasil. Orientadora: Eliana Regina de Freitas Dutra. 258f. Tese (Doutorado em História) - Faculdade de Filosofia e Ciências Humanas, Universidade Federal de Minas Gerais, Belo Horizonte.

KIRSHENBLATT-GIMBLETT, Barbara. 1991. Objects of ethnography. In: KARP, I; LAVINE, S. D. (org.). Exhibiting cultures: the poetics and politics of museum display.

Washington-London: Smithsonian Institution Press.

MAGALHÃES, Aline Montenegro. 2003. Cultuando a saudade... Sobre antiquariado e escrita da história no Museu Histórico Nacional. In: BITTENCOURT, José Neves; BENCHETRIT, Sarah Fassa; TOSTES, Vera Lúcia Bottrel (ed.). História representada: o dilema dos museus. Rio de Janeiro: Museu Histórico Nacional.

MALHANOS, Clara Emília Sanches Monteiro. 2002. Da materialização à legitimação do passado: a monumentalidade como metáfora do Estado: 1920-1945. Rio de Janeiro: Lucerna/Faperj.

MEC-SPHAN/PRÓ-MEMÓRIA. 1982. Bens móveis e imóveis inscritos nos livros do Tombo do Patrimônio Histórico e Artístico Nacional. Brasília.

MICELI, Sérgio. 1987. Sphan: refrigério da cultura oficial. Revista do Patrimônio Histórico e Artístico Nacional, Iphan/MinC, n. 22.

MOTTA, Lia. 1987. O Sphan em Ouro Preto: uma história de conceitos e critérios. Revista do Patrimônio Histórico e Artístico Nacional, Iphan/MinC, n. 22.

PANDOLFI, Dulce (org.). 1999. Repensando o Estado Novo. Rio de Janeiro: FGV.

POMIAN, Krzystof. 1987. Collectioneurs, amateurs et curieux. Paris, Venise: $X V I^{e}$ XVIII siècle. Paris: Gallimard.

RUBINO, Silvana.1996. O mapa do Brasil passado. Revista do Patrimônio Histórico e Artístico Nacional. n. 24, p. 96-115.

SANTOS, Mariza Velloso Motta. 1992. O tecido do tempo: a constituição da ideia de patrimônio cultural no Brasil entre 1920 e 1970. Tese (Doutorado em Antropologia) - UnB, Brasília. 1996. Nasce a academia Sphan. Revista do Patrimônio Histórico e Artístico Nacional. Rio de Janeiro, n. 24.

SANTOS, Myrian Sepúlveda dos. 2006. A escrita do passado em museus históricos. Rio de Janeiro: Garamond, MinC/ Iphan, Demu.

SCHWARCZ, Lilia Moritz. 1993. O espetáculo das raças: cientistas, instituições e questão racial no Brasil, 1870-1930. São Paulo: Companhia das Letras.

WILLIAMS, Daryle. 2001. Culture wars in Brazil: the first Vargas regime, 1930-1945. Durham, London: Duke University Press. 


\begin{abstract}
Resumo
Os estudos sobre o processo de institucionalização de uma política preservacionista no Brasil têm privilegiado a análise do discurso sobre o patrimônio, formulado no âmbito do Sphan, ou o exame das medidas de proteção do acervo arquitetônico, cerne da ação governamental. Poucos mencionam as iniciativas no campo dos museus, sendo este o objetivo principal do artigo, que discute a proposta de criação de museus regionais, tendo como recorte o estado de Minas Gerais, nos anos 1950.
\end{abstract}

Palavras-chave: museus regionais, Sphan, cultura museológica, critérios de formação de acervos

\title{
Abstract
}

Research on the institutionalization of a conservationist policy in Brazil has privileged either the analysis of discourses on heritage, as formulated by the Service for the Protection of Historical and Artistic Heritage (Sphan), or the examination of measures aimed at protecting architectural heritage, which has constituted the core of governmental action in the field. Few studies mention similar endeavors in the field of museums, which constitutes the main objective of this article. I discuss a proposal for the creation of regional museums, taking the state of Minas Gerais in the 1950s as a case study. Key words: regional museums, Sphan, museological culture, criteria for forming collections.

\section{Résumé}

Les études sur l'institutionalisation d'une politique de préservation au Brésil consistent en général en l'analyse du discours sur le patrimoine formulé par le Sphan (Service du Patrimoine Historique et Artistique National) ou en l'examen des mesures de protection du patrimoine architectonique qui constituent l'essentiel de l'action du gouvernement. Un nombre très reduit d'études porte sur l'action des musées. C'est là le but de cet article, qui discute le projet de création de musées régionaux et se concentre sur l'état de Minas Gerais aux années 1950.

Mots-clés: Sphan, musées régionaux, culture muséologique, principes de formation de collections 